\title{
Impact of a residential program on the psychological needs, motivation and physical activity of obese adults: A controlled trial based on Self-Determination Theory
}

\author{
Julie Boiché ${ }^{1,2, *}$, Mathieu Gourlan ${ }^{1,3}$, and Léna Rubin ${ }^{2}$ \\ ${ }^{1}$ Univ Paul Valéry Montpellier 3, Univ. Montpellier, EPSYLON EA 4556, F34000, Montpellier, France \\ ${ }^{2}$ UFR STAPS, Univ. Montpellier, Montpellier, France \\ ${ }^{3}$ Epidaure, Département Prevention de l'Institut régional du Cancer de Montpellier (ICM), Montpellier, France
}

Received 18 July 2017, Accepted 30 July 2018

\begin{abstract}
Purpose: This study aimed to examine the increased benefits of a Self Determination Theory (SDT)based motivational component on psychological needs' fulfillment, self-determined motivation and Physical Activity (PA) of obese patients taking part in a rehabilitation program. Methods: Fourty-nine obese adults $\left(\right.$ mean age $=52$ years, mean $\mathrm{BMI}=38.25 \mathrm{~kg} / \mathrm{m}^{2}$ ) attended a 3 -week residential intervention. Patients in the Motivation group $(n=24)$ received a standard care plus SDT-based intervention (i.e., improved supervised PA sessions + a 1-hour motivational session). Patients in the Control group $(n=25)$ only benefited from standard care. Psychological needs and motivation were measured at baseline, at the end of the program and one month after. PA was measured at baseline and one month after the end of the program. Repeated measures ANOVAs were performed to compare the evolution of the variables between groups. Results: The results indicated that participants from both groups displayed significant changes in their perceived autonomy, relatedness, intrinsic motivation and integrated regulation between the beginning and the end of the program. Next, participants from both groups showed a decrease in perceived relatedness between the end of the program and one month after. Last, the participants from the Motivation group reported greater increase of their PA scores between the beginning of the program and one month after as compared to those in the Control group. Conclusions: Obesity interventions should integrate motivational components in order to promote behavior maintenance after programs have ended.
\end{abstract}

Key words: rehabilitation, exercise, physical inactivity, health behavior maintenance, motivational climate

Résumé - Impact d'un programme résidentiel sur les besoins psychologiques, la motivation et l'activité physique d'adultes obèses: Un essai contrôlé basé sur la théorie de l'autodétermination. Objectif: Cette étude visait à examiner les bénéfices d'une composante motivationnelle basée sur la théorie de l'Autodétermination (TAD) pour la satisfaction des besoins psychologiques fondamentaux, la motivation autodéterminée et l'activité physique (AP) de personnes obèses participant à un programme de réhabilitation. Méthode : Quarante-neuf adultes obèses (Âge moyen $=52 \mathrm{ans} ;$ IMC moyen $=38,25 \mathrm{~kg} / \mathrm{m}^{2}$ ) ont participé à une intervention résidentielle d'une durée de 3 semaines. Les patients du groupe Motivation $(N=24)$ ont bénéficié de la prise en charge standard, ainsi que d'une intervention basée sur la TAD (i.e., sessions d'AP supervisées améliorées, session motivationnelle de 1 heure). Les patients du groupe Contrôle $(N=25)$ ont bénéficié de la prise en charge standard. Les besoins psychologiques et la motivation ont été mesurés au début et à la fin du programme et un mois après. L'AP a été mesurée au début du programme et un mois après la fin de celui-ci. Des ANOVAs à mesures répétées ont été conduites afin de comparer l'évolution des variables entre les deux groupes. Résultats: Les résultats indiquent que les participants des deux groupes ont montré une augmentation significative d'autonomie, d'affiliation, de motivation intrinsèque et de régulation intégrée, entre le début et la fin du programme. De plus, les participants des deux groupes ont connu une baisse de leur niveau d'affiliation entre la fin du programme et un mois après. Enfin, les participants du groupe Motivation ont rapporté une augmentation plus importante de leur niveau d'AP entre le début du programme et un mois après sa fin, par

*Auteur correspondant: julie.boiche@umontpellier.fr 
rapport à ceux du groupe Contrôle. Conclusions: Les interventions auprès de personnes obèses devraient intégrer des composantes motivationnelles afin de promouvoir le maintien d'un changement de comportement après que les programmes soient terminés.

Mots clés : réhabilitation, exercice, inactivité physique, maintien des comportements de santé, climat motivationnel

Physical Activity (PA) represents nowadays the cornerstone of rehabilitation programs in obese patients (Pedersen \& Saltin, 2006). Adopting regular PA is crucial for weight management, together with balanced dietary behavior (Donnelly et al., 2009). Unfortunately, previous research indicated that most obese patients are insufficiently physically active (Davis, Hodges, \& Gillham, 2006) and that they tend to have difficulties to maintain healthrelated behaviors once structured PA programs are over (Wing \& Hill, 2001). Research on motivational processes is thus central to a better understanding of the psychological factors likely to lead to PA maintenance or its cessation following a rehabilitation program, given the chronic character of obesity. Health psychologists increasingly claim that theory-based interventions are needed to provide insights as to why those interventions display such effects (Gardner et al., 2014). A recent meta-analysis supported the effectiveness of Self-Determination Theory (SDT)-based interventions promoting PA in adults, including obese patients (Gourlan et al., 2016).

Basically, SDT posits that human behaviors reflect qualitatively distinct motivations that can be characterized by their level of self-determination (Deci \& Ryan, 2000). From the least to the most self-determined form, SDT distinguishes amotivation (perceiving no interest in a behavior), external regulation (adopting a behavior to gain rewards or avoid punishment), introjected regulation (acting through interiorized pressures to enhance selfperceptions or avoid negative feelings), identified regulation (performing a behavior to reach a personally valued goal), integrated regulation (conceiving a behavior as congruent with individuals' lifestyle and core values), and intrinsic motivation (performing a behavior for the inherent pleasure and satisfaction it provides). SDT further hypothesizes that individuals' motivation will be as much self-determined as their psychological needs of autonomy (feeling of being at the origin of one's behavior), competence (feeling effective) and relatedness (feeling understood and accepted by others), are fulfilled.

A recent meta-analysis confirmed the validity of SDT to account for mental, physical and behavioral outcomes in the health context ( $\mathrm{Ng}$ et al., 2012), and a review performed by Teixeira, Carraça, Markland, Silva and Ryan (2012) reported a high level of evidence concerning the role of self-determined motivation and perceived competence in the adoption of an active lifestyle. Similar results were reported for studies specifically exploring the motivational determinants of PA practice among obese population (Silva, Markland et al., 2010). From this, SDT has been considered as a relevant framework in the health education of this population (Teixeira, Silva, Mata, Palmeira, \& Markland, 2012). However, Silva, Marques and Teixeira (2014) underlined that there were insufficient efforts of researchers to link intervention techniques to theoretical constructs, which limits the scope of interventional research based on SDT.

Among adult obese patients, Silva, Viera et al. (2010) examined whether a program of health education relative to $\mathrm{PA}$, nutrition, and body image, in an autonomy-supporting environment, would generate more appropriate behaviors and increased weight loss than a general health education program. At the end of the 12-month program, patients in the intervention group showed increased weight loss, as well as higher levels of self-determined motivation and PA behavior than those in the control group. Hsu, Buckworth, Focht, and O'Connell (2013) compared in a feasibility study an exercise-only program to a SDT-based intervention with eight sessions including exercise training, PA change focus groups, self-regulatory skills, and social resources. Both at the end of the program and one month after, participants in the intervention group displayed higher increase in autonomy satisfaction, self-determined motivation, and PA goals. Of note, social contact duration was controlled during both these programs (Hsu et al., 2013; Silva, Vieira et al., 2010).

Taken as a whole, the results of these two studies tend to confirm the beneficial impact of SDT-based interventions on SDT variables and PA in obese adults, notably during the program. Nonetheless, no previous interventions were carried out in the case of a residential program, in which patients remain in a clinical setting during several consecutive weeks. Sometimes preferred to ambulant treatment - during which patients receive interventions during the day but go back to their home every night - in particular in the case of severe obesity (Martins, Strommen, \& Kulseng, 2013), residential programs are characterized by a permanent support of health professionals (Bleich, Huizinga, Beach, \& Cooper, 2010). However, no data are currently available concerning their impact on the motivation of obese adults. It thus appears interesting to explore the efficacy of a SDT-based intervention in this context.

Additionally, it can be noted that the specific evolution of motivational variables between the end of the intervention and several weeks or months after the end of the intervention was not explored by previous research. The absence of such a comparison prevents the possibility to statistically test the extent to which each group displays an increase, decrease or maintenance of 
its level on the variables of interest, during a period where individuals do not benefit from any support and have to cope with the challenges of their daily environment (Wang, Brownell, \& Wadden, 2004), which appears as particularly relevant in the context of residential programs (Martins et al., 2013).

In summary, the present study aimed at examining the impact of a SDT-based intervention in addition to a residential program on the psychological needs, motivations and PA of obese adults. Based on the tenets of SDT (Deci \& Ryan, 2000) and currently available literature on SDT-based previous interventions performed among obese adults, we tested the following hypotheses:

- hypothesis 1: In line with the results of Hsu et al. (2013) and Silva, Vieira et al. (2010), participants in the Motivation group will demonstrate greater increase in psychological needs and self-determined forms of motivation, but higher decrease in controlled forms of motivation, between the beginning and the end of the program, compared to participants in the Control group (T1-T2 comparison);

- hypothesis 2: In line with the results of Hsu et al. (2013), participants in the Motivation group will demonstrate lower decrease in psychological needs and self-determined forms of motivation, and lower increase in controlled forms of motivation, between the end of the program and one month after, compared to participants in the Control group (T2-T3 comparison);

- hypothesis 3: In line with the results of Hsu et al. (2013), participants in the Motivation group will show greater improvement of PA between baseline and one month after the end of the program, compared to participants in the Control group (T1-T3 comparison).

\section{Method}

\subsection{Participants}

The participants were obese adults attending a clinic in the West of France. They were grouped in 4-patient groups and benefited of a 3-week medical, dietetic, and exercise residential program. The conduct of the study was consistent with the principles of the declaration of Helsinki relative to scientific research ethics. The study's inclusion criteria were: being obese $\left(\mathrm{BMI}>30 \mathrm{~kg} / \mathrm{m}^{2}\right)$ and having read and signed an informed consent. The exclusion criteria were: having problems of literacy or medical contraindication pertaining PA. The design of the study was a controlled trial (i.e., patients were not included simultaneously nor were they randomized within groups). Motivation and Control groups were not matched on any variable. Twenty-five participants were recruited to constitute the Control group among patients who attended the clinic between October and December 2012 $\left(M_{\text {age }}=54.4 \pm 9.5 ; 72 \%\right.$ of women; $\left.M_{\text {BMI }}=39.1 \pm 4.6\right)$; 24 participants were included to constitute the Motivation group among patients attending the clinic between January and March $2013 \quad(M$ age $=49.5 \pm 13.5 ; 75 \%$ of women; $M_{\mathrm{BMI}}=37.4 \pm 5$ ). There were no significant between-group differences in terms of baseline characteristics, albeit age $(\mathrm{t}(47)=1.47, \quad p=.15)$ or BMI $(\mathrm{t}(47)=1.24, p=.22)$.

\subsection{Procedure}

\subsubsection{Control group}

Participants in the Control group benefited from standard care. Regarding PA, walking sessions were scheduled every morning. The patients were separated in sub-groups according to their fitness level: patients with the lowest physical fitness (level 1) had 30-minute walking sessions with the goal of covering a maximal distance; patients with higher levels of physical fitness (level2) aimed at completing a 5-kilometer tour during a 1-hour session. For all patients, 50-minute sessions of physical rehabilitation were also scheduled every day with a physical therapist in a dedicated room with mats and ergometers.

\subsubsection{Motivation group}

The dose of PA proposed was comparable to standard care. However, the motivational climate established during the sessions was improved. The PA sessions were administered by a trained Adapted Physical Activity teacher (Msc) and were specifically designed to support the patients' psychological needs (Edmunds, Ntoumanis, \& Duda, 2009; Hsu et al., 2013). To sustain autonomy, the participants could choose a moderate intensity and adjust it personally depending on their feelings of breathlessness during the walking sessions; otherwise they could choose to receive explanations on the respective effects of various intensities and experience them at the occasion of different sessions. Collective PA sessions were programmed to promote relatedness perceptions. Competitive aspects were banished during all the PA sessions and participants were encouraged to care for and support each other. Last, to promote competence, the supervisor adapted PA sessions to propose an optimal challenge for each patient and provided positive feedback after each attempt.

Second, in addition to the PA sessions presented above, an individual 60-minute motivational session led by the Adapted Physical Activity teacher was implemented. Based on existing recommendations (Sheldon, Williams, \& Joiner, 2003) and previous research (Fortier, Sweet, O'Sullivan, \& Williams, 2007; Silva, Vieira et al., 2010), this session pursued two objectives; it aimed at (a) considering the experience and feelings of the patient regarding $\mathrm{PA}$ since the beginning of the residential program; and (b) discussing about the perspectives of PA practice after the intervention has ended. Perceived competence was supported through an evaluation of the problems encountered, the research of alternatives (including the identification of structures proposing adapted PA outside the clinic), the evocation of behavior change outcomes, and goal setting. Perceived autonomy was supported by a non-coercive approach, the exploration of various possible options, the elaboration of the 
project by the patient him/herself, and encouragements to choose a personal action plan. Perceived relatedness was sustained by the practitioner's absence of judgment, empathy, and warm attitude.

\subsection{Measures}

Psychological needs and motivations were measured at all times of measurement (i.e., T1, T2 and T3). PA was only measured at T1 and T3. Indeed, because the level of PA during the program was dependent on the dose fixed by the clinic and should not vary according to patients' motivation this variable was not assessed at T2. Otherwise, the questionnaires were administered in the clinic at $\mathrm{T} 1$ and T2. As T3 was performed one month after the end of the program, the questionnaires were sent by mail to each patient for this time of measurement.

\subsubsection{Psychological needs}

The scale validated in French by Gillet, Rosnet and Vallerand (2008) was used to assess participants' perceptions of autonomy (5items; e.g., "I usually feel free to express my ideas and opinions"), competence (5items; e.g., "I have the impression that I am doing good"), and relatedness (5items; e.g., "I feel at ease with other people"). Following the stem "How do you perceive your PA practice?", participants answer to each proposition using a Likert scale ranging from 1 ("Not at all true") to 7 ("Totally true"). Factorial analysis supported the unidimensional nature of each of the subscales (eighenvalue superior to 1 for only 1 factor; minimum factor weight $=.35$ ). The mean internal consistencies across the three measures were equal to $\alpha$ autonomy $=.69, \alpha$ relatedness $=.81$, and $\alpha$ competence $=.63$. The scores were estimated by computing the mean of the 5 answers (after scores were reversed for three negative items of the competence scale).

\subsubsection{Self-determined motivation}

The "Echelle de Motivation envers l'Activité Physique en contexte de Santé" (EMAPS) (i.e., "Motivation Scale toward Health-Oriented Physical Activity") (Boiché, Gourlan, Trouilloud, \& Sarrazin, in press) was employed to assess the various forms of PA motivation outlined by SDT through 3-item subscales: intrinsic motivation (e.g., "For the pleasure I experience when I practice PA"), integrated regulation (e.g., "Because PA is part of the way I have chosen to live my life"), identified regulation (e.g., "Because I think that PA will enable me to feel better"), introjected regulation (e.g., "Because I would feel bad if I did not make this effort"), external regulation (e.g., "Because some people around pressure me to do it"), and amotivation (e.g., "Frankly, I practice PA but I do not see the point"). Following the stem "Why do you practice regular PA ?", participants answer to each proposition using a Likert scale ranging from 1 ("Not at all true") to 7 ("Totally true"). In the current sample, factorial analysis supported the unidimensional nature of each of the subscales (eighenvalue superior to 1 for only one factor; minimum factor weight $=.50$ ). The internal consistencies across the three measures were equal to $\alpha_{\text {intrinsic }}=.71, \alpha_{\text {integrated }}=.81, \alpha_{\text {identified }}=.79, \alpha_{\text {introjected }}=.57$, $\alpha_{\text {external }}=.85$, and $\alpha$ amotivation $=.78$.

\subsubsection{Physical activity}

A self-report questionnaire (Voorrips, Ravelli, Dongelmans, Deurenberg, \& Van Staveren, 1991) was used to assess PA in patients within their day-to-day environment (i.e., chores, transportation, leisure activities, and sports). A global score was computed, taking into account first, the behavioral profile of the participants in their daily lives, and next, the intensity of each sporting activity or leisure time PA practiced in Metabolic Equivalent of Task (light - from 4 to 7 METS: coefficient 0.76 ; moderate - from 7 to 10 METs: coefficient 1.26) (McCullough et al., 2006), based on a compendium of mean energy expense (Ainsworth et al., 2011), combined with the frequency of their adoption (during the weeks, and overall the seasons). This questionnaire was previously employed to assess PA in obese patients (Romain et al., 2009).

\subsection{Data analysis}

At Time 3 , only 36 of the 49 participants provided complete data. After verifying that the data were not MNAR (i.e., no significant pattern in regard to the variables of the study emerged based on participation or not to Time 3), we applied a multiple imputation program to replace missing observations by the most plausible values for psychological needs, motivation and self-report physical activity ${ }^{1}$. In order to test our first two hypotheses relative to the evolution of basic psychological needs and motivation in both groups of participants, 3 (times) $\times 2$ (groups) repeated measures ANOVAs were conducted. Due to the multiplication of tests, a Bonferroni correction was applied (for an alpha risk at .05, the significance threshold was fixed at $.05 / 9=.0055)$. Regarding the third hypothesis on PA behavior, a 2 (times) $\times 2$ (groups) repeated measures ANOVA was run. In cases where significant effects emerged, Newman-Keuls post-hoc analyses were carried out to examine subgroups differences. Effect sizes (i.e., Cohen's $d$ ) were calculated to inform on the magnitude of the significant changes reported.

\section{Results}

Table 1 presents the mean and standard deviation of all variables for each time of data collection and Table 2 indicates the results of the repeated measures ANOVAs

\footnotetext{
1 The same analysis strategy was conducted in the sample of 36 participants who provided complete data, including PA at T3 $\left(N_{\text {Control group }}=19 ; N_{\text {Motivation group }}=17\right)$. The conclusions were exactly similar to those presented in the article. We decided to present the analyses carried out on the whole sample, in order to have more statistical power.
} 
Table 1. Mean scores and standard deviations at the different times of data collection.

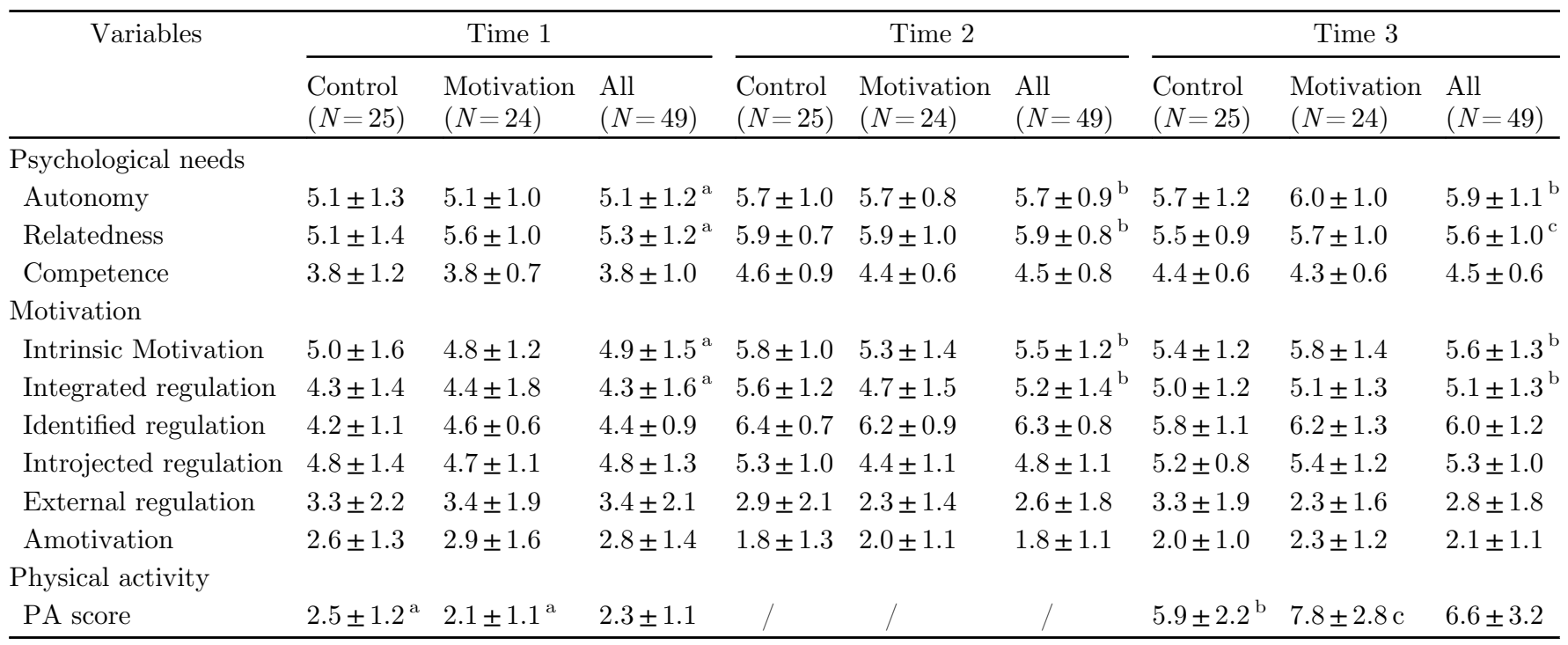

When significant effects were obtained in ANOVAs, post-hoc tests were conducted. To specify the results of those tests in the table, same supercripts letters indicates no between-group differences, while different letters indicate significant differences at $p=.05$.

Table 2. Results of the repeated measures ANOVAs $(N=49)$.

\begin{tabular}{|c|c|c|c|c|c|c|c|c|c|}
\hline \multirow[t]{2}{*}{ Variables } & \multicolumn{3}{|r|}{ Group } & \multicolumn{3}{|r|}{ Time } & \multicolumn{3}{|c|}{ Group*Time } \\
\hline & $F$ & $p$ & partial $\eta^{2}[95 \% \mathrm{CI}]$ & $F$ & $p$ & partial $\eta^{2}[95 \% \mathrm{CI}]$ & $F$ & $p$ & partial $\eta^{2}[95 \% \mathrm{CI}]$ \\
\hline \multicolumn{10}{|l|}{ Psychological needs } \\
\hline Autonomy & 0.06 & .800 & $.00[.00-.05]$ & 10.53 & .001 & $.17[.05-.29]$ & 0.55 & .579 & $.01 \cdot . .00-.07[]$ \\
\hline Relatedness & 0.09 & .766 & $.00[.00-.07]$ & 9.84 & .001 & $.16[.05-.28]$ & 0.17 & .847 & $.00[.00-.04]$ \\
\hline Competence & 1.96 & .176 & $.04[.00-.18]$ & 1.22 & .299 & $.02[.00-.10]$ & 1.68 & .191 & $.03[.00-.11]$ \\
\hline \multicolumn{10}{|l|}{ Motivation } \\
\hline Intrinsic Motivation & 0.32 & .573 & $.01[.00-.11]$ & 11.95 & .001 & $.15[.06-.31]$ & 2.41 & .170 & $.04[.00-.13]$ \\
\hline Integrated regulation & 2.30 & .136 & $.04[.00-.19]$ & 17.07 & .001 & $.20[.11-.38]$ & 3.22 & .040 & $.06[.00-.16]$ \\
\hline Identified regulation & 0.23 & .632 & $.01[.00-.10]$ & 4.28 & .016 & $.08[.00-.18]$ & 1.46 & .238 & $.03[.00-.10]$ \\
\hline Introjected regulation & 3.18 & .081 & $.06[.00-.21]$ & 4.87 & .010 & $.09[.01-.20]$ & 4.88 & .009 & $.09[.01-.20]$ \\
\hline External regulation & 3.19 & .080 & $.06[.00-.21]$ & 3.95 & .217 & $.03[.00-.17]$ & 0.61 & .543 & $.01[.00-.07]$ \\
\hline Amotivation & 0.78 & .381 & $.01[.00-.13]$ & 4.53 & .013 & $.08[.00-.19]$ & 0.06 & .941 & $.00[.00-.02]$ \\
\hline \multicolumn{10}{|l|}{ Physical activity } \\
\hline PA score & 5.31 & .026 & $.10[.00-.27]$ & 141.89 & .001 & $.75[.61-.82]$ & 7.49 & .009 & $.13[.01-.31]$ \\
\hline
\end{tabular}

Control group $(N=25)$, Motivation group $(N=24) .3$ (times) $\times 2$ (groups) repeated measures ANOVAs were conducted for basic psychological needs and motivation. A 2 (times) $\times 2$ (groups) repeated measures ANOVA was conducted for physical activity.

conducted. Taken as a whole, the ANOVAs notably revealed a significant Time effect for perceived autonomy and relatedness, as well as intrinsic motivation and integrated motivation. However, a significant Time X Group effect was found only for self-report PA. Regarding the hypotheses of the study specifically, post-hoc analyses notably revealed that:

- H1 (i.e., T1-T2 comparison) was not supported. Several significant changes appeared between baseline and the end of the program for the whole sample, i.e., an increase in perceived autonomy $(d=.57)$, relatedness $(d=.59)$, intrinsic motivation $(d=.44)$ and integrated regulation $(d=.60)$. However those changes were not significantly different according to group membership (see Tab. 2);

- H2 (i.e., T2-T3 comparison) was not supported. In both groups, the degree of satisfaction of autonomy and competence did not change, neither motivation scores. Of note, the participants of both groups showed a decrease in perceived relatedness after the end of the program $(d=-.33$; see Tab. 2$)$;

- H3 (i.e., T1-T3 comparison) was supported (see Fig. 1). The level of self-report PA significantly increased in both groups following the intervention, but this increase was significantly higher among patients in the Motivation group $(d=2.68)$, compared to those in the Control group $(d=1.92)$. 


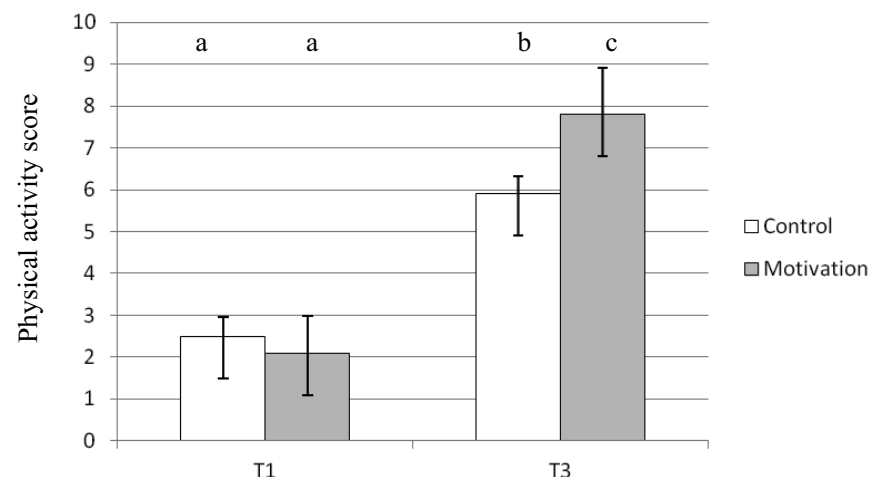

Fig. 1. Changes in physical activity according to group membership Note: Same letter indicates no differences $(p>.05)$.

\section{Discussion}

The present study aimed at examining the impact of including an SDT-based intervention in a standard residential program on the psychological needs, motivations and self-report PA of obese adults. Our first hypothesis concerning the differences between groups during the residential program was not supported by the data. Participants in both groups showed significant increase in their psychological needs and self-determined motivation during the program. Thus, including SDT-based components in a residential program among obese adults did not have additional impact on psychological needs and motivation during the program, in comparison to standard care. The concept of residential program to treat obesity among adults is relatively new (Martins et al., 2013). Some authors suggested that the constant presence in a program to practice PA may be perceived as pressuring by some patients (Verloigne et al., 2011), which from an SDT viewpoint may thwart psychological needs. Others have however hypothesized that those programs represent an arena for the development of close relationships and personal support with patients (Dahl, Rise, Kulseng, \& Steinsbekk, 2014), which from an SDT viewpoint may rather support psychological needs. The significant evolution of both psychological needs and self-determined motivation during the program for the Control group tends to support the latter hypothesis. The absence of higher impact of the SDT intervention could be due to the fact that the standard residential program optimally supported psychological needs of obese patients. Future research should address this issue by measuring the level of perceived psychological needs support of patients by health care professionals during the PA sessions of residential programs.

Next, our second hypothesis stated that the motivational benefits of the program should last more in patients from the additional motivational components. This hypothesis was not supported either, and all the tendencies observed were comparable between groups. Patients globally maintained their levels of autonomy, competence and motivation one month after the end of the program. However, participants of both groups reported a decrease in perceived relatedness between the end of the program and one month after. This may be explained by the fact that when returning to their daily environment, patients had perceived less support to practice PA from important others (e.g., friends, family) as compared to the support from which they had benefited during the residential program. Future research should confirm this hypothesis by exploring the role of important others in the evolution of motivational variables toward $\mathrm{PA}$ after the end of a residential rehabilitation program implemented among obese adults. A potential interesting perspective of such a research program could be to implement some motivational support sessions among important others in order to help them support the psychological needs of their close ones after the residential program has ended.

Last, we hypothesized that participants in the Motivation group would ultimately display higher increase of their self-report PA behavior, compared to those in the Control group, which was supported by the results. The addition of SDT-based components was effective in promoting increased behavioral change one month after the end of a residential program in obese patients. The motivational strategies employed in this research appear rather effective, considering the low cost associated therewith. Indeed, the adaptation of supervised PA sessions as well as the implementation of a single 60minute motivational session were enough to achieve this differentiated outcome. Motivational interventions represent a flexible approach that can be easily incorporated and adapted to different contexts or nature of PA interventions to enhance both behavior initiation and maintenance (McGrane, Galvin, Cusack, \& Stokes, 2015). In the current study, no motivational variable emerged as potentially explaining the differentiated pattern of behavior. During supervised PA sessions or the motivational session, the Motivation group benefited from additional components such as the possibility to adjust or adapt the intensity of their PA, discussions of the perspectives of $\mathrm{PA}$ practice after the intervention has ended, identification of potential barriers to practice, or search of alternatives. Such components are recognized to have a beneficial impact on theoretical variables such as action planning (i.e., specifying when, where and how to adopt a given behavior) or coping planning (i.e., anticipating situations that endanger the performance of intended behavior) (Sniehotta, Schwarzer, Scholz, \& 
Schuz, 2005), which were not measured in the present study. It may be thus possible that for obese people of the Motivation group the impact of the intervention on those variables has in turn facilitated the translation of their autonomous motivation into actual behavior when they returned to their daily environment (Koestner, Lekes, Powers, \& Chicoine, 2002).

This study presents several limitations that should be kept in mind when interpreting the results. First, participants could not be randomized into the intervention versus control groups, because the trained Adapted Physical Activity teacher who led the SDT-based intervention was only present in the establishment for a discrete period of time. If preliminary analyses do not indicate any baseline between-group differences, the controlled trial design never totally ensures that unmeasured social, economic, cultural, or clinical variables do not account for the apparent intervention effect (see Axelrod \& Hayward, 2006). The results observed in this research should thus be confirmed using a design providing higher level of evidence such as randomized controlled trial. Next, the self-reported nature of data related to PA tends to limit the validity of the results (Slootmaker, Schuit, Chinapaw, Seidell, \& van Mechelen, 2009), as does the absence of other objective criterion to evaluate the effects of the program such as BMI change. A social desirability bias may indeed have occurred when participants responded to the questionnaire. An interesting perspective for future studies would thus be to combine both "objective" (e.g., pedometers, accelerometers) and self-reported measures of PA to address this issue. Finally, the current study is hampered by the absence of control of social contact time. There is actually a possibility that the differentiated patterns of outcomes observed are explained by a more important attention devoted to participants in the Motivation group. Future research should thus explore the extent to which a similar motivational intervention would display similar benefits while controlling for contact time in the Control group.

In conclusion, keeping these limitations in mind, the results of the present study reports the benefits of including motivational components into a rehabilitation program implemented among obese adults. More precisely, patients who benefited from the SDT-based intervention reported a higher increase in their PA practice between the beginning of the program and one month after. Future research should replicate those encouraging results on a larger sample of obese adults and explore the impact of SDT motivational components on a longer period after a residential obesity program has ended (e.g., 6 months up to 1 year).

\section{Authors' contribution}

Julie Boiché significantly contributed to the conceptualization of the study and hypotheses, literature review, construction of the study design (including the choice of the measurement tools), determination of the analysis strategy and conduct of the statistical tests, interpretation of the results, writing of the manuscript (introduction, results, discussion, conclusion), and the answer to reviewers' comments.

Mathieu Gourlan significantly contributed to the literature review, determination of the analysis strategy and conduct of the statistical tests, interpretation of the results, writing of the manuscript (introduction, discussion, conclusion), and the answer to reviewers' comments.

Léna Rubin significantly contributed to the literature review, construction of the study design and operationalization, writing of the manuscript (method), and the answer to reviewers' comments.

\section{Conflicts of interest}

The authors declare that they have no conflicts of interest in relation to this article.

\section{References}

Ainsworth, B.E., Haskell, W.L., Hermmann, L.D., Meckes, N., Bassett, D.R. Jr, Tudor-Locke, C. (2011). 2011 Compendium of Physical Activities: a second update of codes and MET values. Medicine and Science in Sports and Exercise, 43/8, 1575-1581. DOI: 10.1249/MSS.0b013e31821ece12.

Axelrod, D.A., \& Hayward, R. (2006). Nonrandomized Interventional Study Designs (Quasi-Experimental Designs). In Clinical Research Methods for Surgeons (pp. 63-76). Totowa, NJ: Humana Press. https://doi.org/10.1007/978-1-59745-230-4_4.

Bleich, S.N., Huizinga, M.M., Beach, M.C., \& Cooper, L.A. (2010). Patient use of weight-management activities: a comparison of patient and physician assessments. Patient Education and Counseling, 79, 344-350. https://doi.org/ 10.1016/j.pec.2010.01.020.

Boiché, J., Gourlan, M., Trouilloud, D., \& Sarrazin, P. (In press). Development and validation of the "Echelle de Motivation envers l'Activité Physique en contexte de Santé" (EMAPS): A motivation scale toward health-oriented physical activity in French. Journal of Health Psychology.

Dahl, U., Rise, M. B., Kulseng, B., \& Steinsbekk, A. (2014). Personnel and participant experiences of a residential weightloss program. A qualitative study. PloS One, 9, e100226. https://doi.org/10.1371/journal.pone.0100226.

Davis, J.N., Hodges, V.A., \& Gillham, M.B. (2006). Physical activity compliance: differences between overweight/obese and normal-weight adults. Obesity, 14, 2259-65. https://doi. org/10.1038/oby.2006.265.

Deci, E.L., \& Ryan, R.M. (2000). The "what" and "why" of goal pursuits: human needs and the self-determination of behavior. Psychological Inquiry, 11, 227-268. https://doi.org/ 10.1207/S15327965PLI1104_01.

Donnelly, J.E., Blair, S.N., Jakicicic, J.M., Manore, M.M., Rankin, J.W., \& Smith, B.K. (2009). American College of Sports Medicine Position Stand. Appropriate physical activity intervention strategies for weight loss and prevention of weight regain for adults. Medicine and Science in Sports and Exercise, 41, 459-471. https://doi.org/10.1249/ MSS.0b013e3181949333.

Edmunds, J., Ntoumanis, N., \& Duda, J. (2009). Helping your clients and patients take ownership over their exercise: fostering exercise adoption, adherence, and associated wellbeing. ACSM's Health \& Fitness Journal, 13, 20-25. https: // doi.org/10.1249/FIT.0b013e3181a1c2c4. 
Fortier, M.S., Sweet, S.N., O'Sullivan, T.L., \& Williams, G.C. (2007). A self-determination process model of physical activity adoption in the context of a randomized controlled trial. Psychology of Sport and Exercise, 8, 741-757. https:// doi.org/10.1016/j.psychsport.2006.10.006.

Gardner, B., Broström, A., Nilsen, P., Hrubos Ström, H., Ulander, M., Fridlund, B., Johansson, P. (2014). From "does it work?" to "what makes it work?": The importance of making assumptions explicit when designing and evaluating behavioural interventions. European Journal of Cardiovascular Nursing, 13, 292-294. https://doi.org/10.1177/ 1474515114531688.

Gillet, N., Rosnet, E., \& Vallerand, R.J. (2008). Développement d'une échelle de satisfaction des besoins fondamentaux en contexte sportif [Development of a scale of satisfaction of the fundamental requirements in sporting context]. Canadian Journal of Behavioural Science, 40, 230-237. https://doi. org $/ 10.1037 / \mathrm{a} 0013201$.

Gourlan, M., Bernard, P., Bortolon, C., Romain, A. J., Lareyre, O., Carayol, M., Boiché, J. (2016). Efficacy of theory-based interventions to promote physical activity. A meta-analysis of randomised controlled trials. Health Psychology Review, 10, 50-66. https://doi.org/10.1080/17437199.2014.981777.

Hsu, Y.-T., Buckworth, J., Focht, B.C., \& O'Connell, A. (2013). Feasibility of a Self-Determination Theory-based exercise intervention promoting Healthy at Every Size with sedentary overweight women: Project CHANGE. Psychology of Sport and Exercise, 14, 283-292. https://doi.org/10.1016/j.psy chsport.2012.11.007.

Koestner, R., Lekes, N., Powers, T.A., \& Chicoine, E. (2002). Attaining personal goals: Self-concordance plus implementation intentions equals success. Journal of Personality and Social Psychology, 83/1, 231-244. https://doi.org/10.1037// 0022-3514.83.1.231.

Martins, C., Strommen, M., \& Kulseng, B. (2013). Longer length of first stay in intermittent residential programmes is associated with larger weight loss at 1 and 2 years. Obesity Facts, 6, 288-296. https://doi.org/10.1159/000353641.

McCullough, P.A., Gallagher, M.J., DeJong, A.T., Sandberg, K. R., Trivax, J.E., Alexander, D., Franklin, B.A. (2006). Cardiorespiratory fitness and short-term complications after bariatric surgery. Chest, 130/2, 517-525. https://doi.org/ 10.1378/chest.130.2.517.

McGrane, N., Galvin, R., Cusack, T., \& Stokes, E. (2015). Addition of motivational interventions to exercise and traditional Physiotherapy: a review and meta-analysis. Physiotherapy, 101, 1-12. https://doi.org/10.1016/j.physio.2014.04.009.

Ng, J.Y.Y., Ntoumanis, N., Thogersen-Ntoumani, C., Deci, E.L., Ryan, R.M., Duda, J.L., \& Williams, G.C. (2012). SelfDetermination theory applied to health contexts: A metaAnalysis. Perspectives on Psychological Science, 7, 325-340. https://doi.org/10.1177/1745691612447309.

Pedersen, B.K., \& Saltin, B. (2006). Evidence for prescribing exercise as therapy in chronic disease. Scandinavian Journal of Medicine 63 Science in Sports, 16 (Suppl 1), 3-63. https:// doi.org/10.1111/j.1600-0838.2006.00520.x.

Romain, A.-J., Attal, J., Hermès, A., Capdevielle, D., Raimondi, R., Boulenger, J.-P., \& Brun, J.-F. (2009). Effets d'un réentraînement en endurance au LIPOXmax chez des patients psychiatriques traités par psychotropes [Effects of endurance training targeted at the LIPOXmax in psychiatric patients treated by neuroleptics]. Science 8 Sports, 24, 265268. https://doi.org/10.1016/j.scispo.2009.01.006.

Sheldon, K., Williams, G., \& Joiner, T. (2003). Self-determination theory in the clinic: Motivating physical and mental health. New Haven: Yale University Press.

Silva, M.N., Markland, D., Vieira, P.N., Coutinho, S.R., Carraça, E.V., Palmeira, A.L., Teixeira, P.J. (2010). Helping overweight women become more active: Need support and motivational regulations for different forms of physical activity. Psychology of Sport and Exercise, 11, 591-601. https://doi.org/10.1016/j.psychsport.2010.06.011.

Silva, M.N., Vieira, P.N., Coutinho, S.R., Minderico, C.S., Matos, M.G., Sardinha, L.B., \& Teixeira, P.J. (2010). Using self-determination theory to promote physical activity and weight control: a randomized controlled trial in women. Journal of Behavioral Medicine, 33, 110-122. https://doi. org/10.1007/s10865-009-9239-y.

Silva, M.N., Marques, M.M., \& Teixeira, P.J. (2014). Testing theory in practice: The example of self-determination theorybased interventions. European Health Psychologist, 16, 171-180.

Slootmaker, S.M., Schuit, A.J., Chinapaw, M.J., Seidell, J.C., \& van Mechelen, W. (2009). Disagreement in physical activity assessed by accelerometer and self-report in subgroups of age, gender, education and weight status. International Journal of Behavioral Nutrition and Physical Activity, 6, 17. https:// doi.org/10.1186/1479-5868-6-17.

Sniehotta, F.F., Schwarzer, R., Scholz, U., Schuz, B., \& Schüz, B. (2005). Action planning and coping planning for long-term lifestyle change, Theory assessment. European Journal of Social Psychology, 35(December 2004), 565-576. https://doi. org/10.1002/ejsp. 258.

Teixeira, P.J., Carraça, E.V, Markland, D., Silva, M.N., \& Ryan, R.M. (2012). Exercise, physical activity, and self-determination theory: a systematic review. International Journal of Behavioral Nutrition and Physical Activity, 9, 78. https:// doi.org/10.1186/1479-5868-9-78.

Teixeira, P.J., Silva, M.N., Mata, J., Palmeira, A.L., \& Markland, D. (2012). Motivation, self-determination, and long-term weight control. International Journal of Behavioral Nutrition and Physical Activity, 9, 22. https://doi.org/ 10.1186/1479-5868-9-22.

Verloigne, M., De Bourdeaudhuij, I., Tanghe, A., D'Hondt, E., Theuwis, L., Vansteenkiste, M., \& Deforche, B. (2011). Self-determined motivation towards physical activity in adolescents treated for obesity: an observational study. International Journal of Behavioral Nutrition and Physical Activity, 8, 97. https://doi.org/10.1186/ 1479-5868-8-97.

Voorrips, L.E., Ravelli, A.C., Dongelmans, P.C., Deurenberg, P., \& Van Staveren, W.A. (1991). A physical activity questionnaire for the elderly. Medicine and Science in Sports and Exercise, 23, 974-979.

Wang, S.S., Brownell, K.D., \& Wadden, T.A. (2004). Theinfluence of the stigma of obesity on overweight individuals. International Journal of Obesity and Related Metabolic Disorders, 28, 1333-1337. https://doi.org/10.1038/sj.ijo.0802730.

Wing, R.R., \& Hill, J.O. (2001). Successful weight loss maintenance. Annual Review of Nutrition, 21, 323-341. https://doi.org/10.1146/annurev.nutr.21.1.323.

Cite this article as: Boiché J, Gourlan M, \& Rubin L (2018) Impact of a residential program on the psychological needs, motivation and physical activity of obese adults: A controlled trial based on Self-Determination Theory. Mov Sport Sci/Sci Mot, 101, $33-40$ 